\title{
Pleural catheters after thoracoscopic treatment of malignant pleural effusion: a randomized comparative study on quality of life
}

\author{
Francesco Petrella ${ }^{1,2}$, Patrick Maisonneuve ${ }^{3}$, Alessandro Borri ${ }^{1}$, Monica Casiraghi ${ }^{1}$, Stefano Donghi ${ }^{1}$, Sava \\ Durkovic $^{1}$, Niccolo Filippi ${ }^{1}$, Domenico Galetta ${ }^{1}$, Roberto Gasparri ${ }^{1}$, Juliana Guarize ${ }^{1}$, Giorgio Lo Iacono ${ }^{1}$, \\ Alessio Vincenzo Mariolo ${ }^{1}$, Adele Tessitore ${ }^{1}$, Lorenzo Spaggiari ${ }^{1,2}$
}

${ }^{1}$ Department of Thoracic Surgery, European Institute of Oncology, Milan, Italy; ${ }^{2}$ Department of Oncology and Hemato-oncology, University of Milan, Milan, Italy; ${ }^{3}$ Division of Epidemiology and Biostatistics, European Institute of Oncology, Milan, Italy

Contributions: (I) Conception and design: F Petrella, L Spaggiari; (II) Administrative support: F Petrella, A Borri; (III) Provision of study materials or patients: F Petrella, A Borri; (IV) Collection and assembly of data: F Petrella, P Maisonneuve; (V) Data analysis and interpretation: All authors; (VI) Manuscript writing: All authors; (VII) Final approval of manuscript: All authors.

Correspondence to: Francesco Petrella, MD, PhD. Department of Thoracic Surgery, European Institute of Oncology, Via Ripamonti, 435, Milan 20141, Italy. Email: francesco.petrella@ieo.it; francesco.petrella@unimi.it.

\begin{abstract}
Background: Malignant pleural effusion (MPE) complicates many neoplasms and its incidence is expected to rise in parallel with the aging population and longer survival of cancer patients. Although a clear consensus exists on indwelling catheters in patients with poor performance status, no study has hitherto compared different devices in patients requiring temporary or definitive drainage following talc poudrage.

Methods: This is a prospective, two-arm, pilot study on patients with MPE undergoing talc poudrage, comparing two different catheters (Pleur $\mathrm{X}^{\circledR}$ versus Pleurocath ${ }^{\circledR}$ ) positioned because of the inefficacy of the procedure or the high risk of short-term failure. End points of the study were quality of life (QoL), median dyspnea and chest pain assessment by EORTC questionnaires and a $100 \mathrm{~mm}$ visual analog scale, total inhospital length of stay and frequency of serious adverse events.

Results: No difference was observed between the two groups in in mean dyspnea and mean chest pain in any questions of the EORTC QLQ-C30 and QLQ-LC13 questionnaires. Duration of the procedure was significantly longer in the Pleur $\mathrm{X}^{\circledR}$ group versus the Pleurocath ${ }^{\circledR}$ group $(72 \pm 33$ versus $44 \pm 13$ minutes; $\mathrm{P}=0.03)$. No difference was observed between the two groups in total length of hospital stay $(\mathrm{P}=1.00)$ or complication rate $(\mathrm{P}=1.00)$.

Conclusions: For the cohort of patients still needing indwelling pleural catheters (PC) after thoracoscopic talc poudrage, Pleur $\mathrm{X}^{\circledR}$ is suggested when drain removal is unlikely due to short life expectancy or the high chance of pleurodesis failure. Conversely, Pleurocath ${ }^{\circledR}$ should be recommended in all other patients as it is faster to place and easier to remove.
\end{abstract}

Keywords: Malignant pleural effusion (MPE); talc poudrage; indwelling pleural catheter (indwelling PC)

Submitted Jan 17, 2018. Accepted for publication Apr 25, 2018.

doi: $10.21037 /$ jtd.2018.05.49

View this article at: http://dx.doi.org/10.21037/jtd.2018.05.49

\section{Introduction}

Malignant pleural effusion (MPE) is defined as the presence of neoplastic cells in pleural fluid. Like malignant metastatic cells to the pleura, MPE signifies disseminated or advanced disease with reduced life expectancy in cancer patients (1).
Lung cancer in men and breast cancer in women are the most common metastatic tumors to the pleura, together accounting for $50-65 \%$ of all neoplastic effusions $(2,3)$.

The British Thoracic Society pleural disease guidelines recommend aspiration to relieve symptoms in case of known MPE, and thoracoscopic talc poudrage or talc slurry 


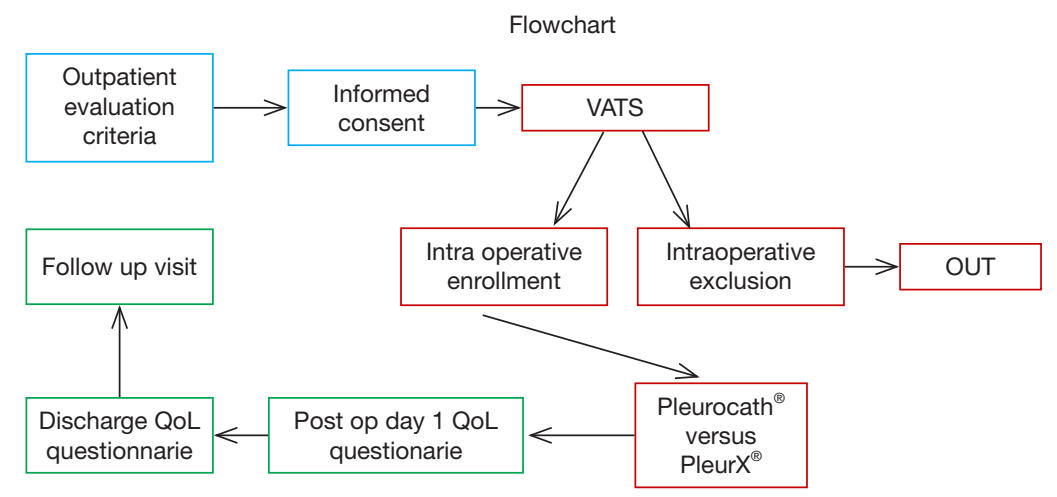

Figure 1 Flowchart.

or chest drain or pleural catheter (PC) when prognosis is longer than one month, depending on lung re-expansion and success or failure of pleurodesis (4).

Several studies have recently compared the effect of PC versus chest tube and talc pleurodesis for relieving dyspnea in patients with MPE, disclosing no significant difference (5) or cost-effectiveness of PC compared with talc in patients with limited survival, although substantial uncertainty surrounds this estimate (6). To date, PC can be considered as first line treatment for MPE (7).

Although a clear consensus exists about IPC in patients with poor performance status or with high surgical risk and short life expectancy (8), no study has compared different devices in patients requiring temporary or definitive drainage following talc poudrage, leaving the clinical choice to the surgeon's personal preference and local availability of the device required.

The goal of this pilot study was to compare quality of life (QoL) in a cohort of MPE patients receiving two different types of PCs normally used in clinical practice $\left(\right.$ Pleur $^{\circledR}$ versus Pleurocath ${ }^{\circledR}$ ). The patients had undergone video-assisted thoracoscopic (VAT) talc poudrage but still needed postoperative IPCs because of the inefficacy of the procedure or the high risk of short-term failure.

\section{Methods}

\section{Study design and duration}

This was a prospective, two-arm, pilot study where patients with MPE undergoing VAT talc poudrage needed postoperative PCs because of the inefficacy of the procedure or the high risk of short-term failure. Twenty patients fulfilling the inclusion criteria were consecutively and alternatively enrolled over a six-month period according to a pre-existing sequence $(\mathrm{A}, \mathrm{B}, \mathrm{A}, \mathrm{B})$ : ten patients received a Pleurocath $^{\circledR}$ catheter and ten received a Pleur $\mathrm{X}^{\circledR}$ catheter.

The PleurX $\mathrm{X}^{\circledR}$ system we used is a 15.5 French silicone catheter with 30 beveled fenestrations along its distal $26 \mathrm{~cm}$ with a Dacron ${ }^{\circledR}$ cuff approximately $36 \mathrm{~cm}$ from the tip. The device has a proprietary safety valve designed to prevent the passage of air or fluid in either direction unless the valve is accessed with an ad hoc proprietary drainage line (9). The Pleurocath $^{\circledR}$ we used is a 10 French $50 \mathrm{~cm}$ long radiopaque catheter with a lateral fenestration along its distal $10 \mathrm{~cm}$, with two marks at 14 and $19 \mathrm{~cm}$ from the tip. We used "asbestos-free" talc (STERITALC ${ }^{\circledR}$ by Novatech SAFrance) (Figure 1).

Ethical and regulatory approval for the study was obtained from the European Institute of Oncology Ethics Committee before recruitment commenced (R574/17IE0607 15.03.2017), and all patients provided written informed consent prior to randomization.

\section{Patient population}

\section{Inclusion criteria}

Adult patients with a confident clinical diagnosis of symptomatic MPE enrolled for VAT talc poudrage but still needing postoperative PCs because of the inefficacy of the procedure or the high risk of short-term failure.

\section{Exclusion criteria}

Age younger than 18 years; expected survival of less than three months; chylothorax; total white blood cell count less than $1,000 / \mu \mathrm{L}$; pregnancy or lactating mothers; irreversible bleeding diathesis; irreversible visual impairment; contraindications to general anesthesia; poor general clinical 
condition (ECOG performance status $\geq 2$ ); patients unable to provide informed consent.

\section{Clinical evaluation and procedures}

\section{Pre-surgery}

Preoperative evaluation included standard functional assessment such as cardiological evaluation, laboratory test and spirometry (if feasible). Pleural effusion was evaluated by chest CT scan. Thoracic surgery consultation confirmed the indication for VAT talc poudrage and anesthesiologist consultation confirmed no contraindications to general anesthesia.

\section{Surgery}

Intraoperative evaluation of lung re-expansion is performed during VAT exploration. The patient was considered eligible for the protocol if lung re-expansion was judged incomplete after gentle positive pressure ventilation (10 $\mathrm{cmH}_{2} \mathrm{O}$, PEEP: 0). This represented a case of "trapped" or "sub total trapped lung" requiring a permanent catheter because of the inefficacy of the procedure or the high risk of short-term failure. Pleur $\mathrm{X}^{\circledR}$ or Pleurocath ${ }^{\circledR}$ catheters were then positioned standardly in a consecutive and alternate way as described above.

\section{Post-surgery}

Daily chest X-ray was performed from day 0 (day of surgical procedure) to discharge and the quality and quantity of drained fluid was monitored. QoL by the European Organization for Research and Treatment of Cancer (EORTC) core questionnaire QLQ-C30 was administered on postoperative day 1 in conjunction with the QLQLC13-a 13-item module for the assessment of QoL in lung cancer patients. Patients received physical examination and chest X-ray on the day of discharge. Completed QoL questionnaires were recorded together with information on dyspnea and chest pain on a $100 \mathrm{~mm}$ visual analog scale. Chest X-ray and physical examination were performed at the 30-day follow-up visit.

\section{Primary endpoint and secondary endpoints}

The primary endpoint of the study was the evaluation of QoL by EORTC QLQ-C30 and QLQ-LC13 questionnaires. The secondary endpoints were: assessing mean dyspnea on a $100 \mathrm{~mm}$ visual analog scale; assessing mean chest pain on a $100 \mathrm{~mm}$ visual analog scale; total in-hospital length of stay from postoperative day 0 to discharge; frequency of serious adverse events (catheter malfunction and displacement rates and the infection rate).

\section{Statistical analysis}

We used the Fisher exact test and non-parametric median test to assess differences in patient characteristics, intervention, hospitalization, complications and QoL scores between the two intervention groups. The distribution of continuous variables was presented by the median and inter-quartile range (IQR). Analyses were performed with SAS software version 9.4 (Cary, NC, USA). All P values were two-sided. A $\mathrm{P}$ value $<0.05$ was considered statistically significant.

\section{Results}

Forty patients entered the study and 20 were intraoperative randomized; among the 20 enrolled patients, eight were males and 12 females. Median age was 67 years (range, 37-86). Median procedure duration (VAT talc poudrage and catheter positioning) was 50 minutes (IQR 24.5). We observed only one complication consisting in pulmonary atelectasis requiring bronchoscopic toilette and noninvasive ventilation cycles. Eight of the 20 positioned catheters $(40 \%)$ were removed in the follow-up period, in seven cases because no pleural effusion recurrence was observed (no fluid drained from catheter and no pleural effusion on chest X-ray) and the catheter was functionally excluded; in one case because the patient was submitted to pleurectomy to treat malignant pleural mesothelioma after talc poudrage and induction chemotherapy. The frequency and entity of drainage regime was mainly regulated by dyspnea symptoms and sometimes confirmed by chest $\mathrm{x}$ ray when strictly needed.

Median duration of in-site catheter stay was 37.0 (IQR 52.5) days in the eight patients who had catheter removal, and 45.0 (IQR 80.5) days in the 12 patients in whom the catheter was left in-site. The oncologic disease was lung cancer in 12 patients (60\%), gynecologic primary tumors in three $(15 \%)$, breast cancer in two $(10 \%)$, mesothelioma in two $(10 \%)$ and prostate cancer in one patient (5\%).

No difference was observed between the two groups in terms of sex $(\mathrm{P}=0.17)$, age $(\mathrm{P}=0.49)$, total length of stay $(\mathrm{P}=1.00)$, complication rate $(\mathrm{P}=1.00)$ or drain removal $(\mathrm{P}=0.65)$. The median duration of the procedure was 
Table 1 Study characteristics

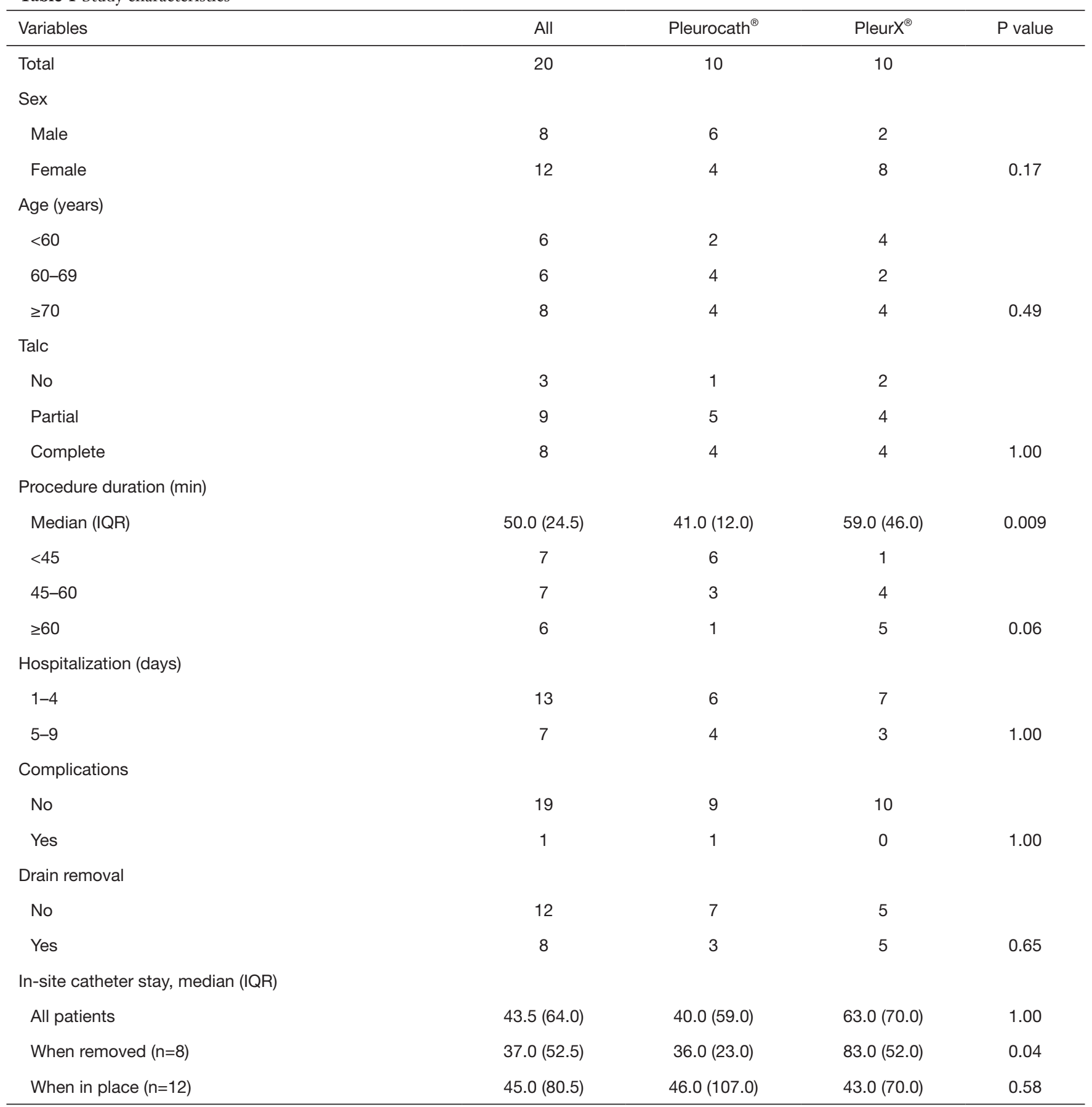

$I Q R$, interquartile range.

significantly longer in the $\mathrm{Pleur} \mathrm{X}^{\circledR}$ group versus the Pleurocath ${ }^{\circledR}$ group [59.0 (IQR 46.0) minutes versus 41.0 (IQR 12.0) minutes; $\mathrm{P}=0.009$ ] (Table 1). No difference was observed between the two groups in any single item of the EORTC QLQ-C30 and QLQ-LC13 questionnaires, global QoL scores, mean dyspnea or mean chest pain on a $100 \mathrm{~mm}$ visual analog scale (Table 2, online: http://jtd. amegroups.com/public/system/jtd/supp-jtd.2018.05.49-1. pdf, http://jtd.amegroups.com/public/system/jtd/suppjtd.2018.05.49-2.pdf). No serious adverse event was 
Table 2 Quality of life

\begin{tabular}{|c|c|c|c|c|}
\hline Global scores & \multicolumn{3}{|c|}{ Median (IQR) } & $P$ value \\
\hline \multicolumn{5}{|l|}{ QLQ-C30 } \\
\hline Global health status & $50.0(16.7)$ & $50.0(16.7)$ & $50.0(25.0)$ & 0.33 \\
\hline Functional score & $77.8(13.8)$ & $78.9(14.3)$ & $77.8(15.6)$ & 0.75 \\
\hline \multicolumn{5}{|l|}{ QLQ-LC13 } \\
\hline Score & $11.6(8.5)$ & $17.4(11.1)$ & $11.1(7.6)$ & 0.08 \\
\hline \multicolumn{5}{|l|}{ Visual analog scale VAS } \\
\hline Thoracic pain & $20.0(32.0)$ & $17.5(27.0)$ & $30.0(35.0)$ & 0.30 \\
\hline
\end{tabular}

IQR, interquartile range; VAS, visual analog scale.

reported in either group.

\section{Discussion}

MPE complicates many neoplasms and its incidence is expected to rise in parallel with the aging population and longer survival of cancer patients (10). Talc pleurodesis was first described in 1935 (11) and remains the mainstay of treatment worldwide. However, there is no consensus on whether the procedure should be performed by talc slurry under local anesthesia during single access medical pleuroscopy or by talc poudrage under general anesthesia during single-lung ventilation thoracoscopic surgery (12).

Pleurodesis is currently recommended by guidelines as a first-line therapy for patients without trapped lung (4). In these cases, lung re-expansion after pleural fluid drainage allows direct contact of both pleurae, thus providing the ideal setting for developing pleuro-pulmonary adhesions due to talc-induced chemical pleuritis.

PC has recently been advocated as the first choice of MPE management in some centers, although there are no data to guide the choice of pleurodesis or PC in individual patients and the treatment used is largely dependent on clinicians' preference (13). Although IPC may represent an alternative to pleurodesis, the device can also play a complementary role of VAT thoracoscopy because it can be left in the chest as a rescue treatment when a high failure rate of talc poudrage is expected.

Although in this case PC cannot be considered as a preventive "insurance", it may result useful for the patients with trapped lung who did not undergo VAT or at least poudrage; moreover, the longer the patient lives, the more likely the fluid recurs thus making PC more useful in patients with longer life expectancy (14).

In fact, after the baseline standard aspiration recommended by BTS guidelines (4), it is not always possible to clearly foresee lung re-expansion by chest X-ray and exclude patients from a possible effective thoracoscopic talc poudrage. Moreover, the development of biologic and immunotherapeutic drugs has driven oncologists' demand for thoracoscopic pleural biopsy for histologic subtyping as pleural cytology is often negative or insufficient.

No study has hitherto compared different types of IPC in this setting and our pilot study aimed to assess if any differences exist between devices. The two devices offered almost identical results in terms of QoL in the early postoperative period, the only significant difference being a longer duration for Pleur $\mathrm{X}^{\circledR}$ positioning. This may be partially due to a necessary learning curve (the Pleur $\mathrm{X}^{\circledR}$ was the new device and Pleurocath ${ }^{\circledR}$ the one traditionally used by all surgeons involved in the study); however-since both procedures are simple-we cannot assume that the time difference between the two procedures is an important factor to draw a conclusion. In terms of cost we spent 33 euros for each Pleurocath ${ }^{\circledR}$ and 476 euros for each PleurX $\mathrm{X}^{\circledast}$ set, for a whole cost of euros 330 for one arm and euro 4.760 for the other.

When needed, Pleurocath ${ }^{\circledR}$ appeared easier to remove as it does not need dissection of scar tissue along the cuff that is properly aimed at stabilizing the drainage and preventing 
dislocation.

Some limits of the study need to be reported. Although this is a prospective study, it is a preliminary pilot investigation whose results need to be confirmed by larger trials. In addition, our endpoints were related to QoL shortly after the procedure, whereas a longer follow-up could provide further data on the long-term reliability of the PC devices and further studies are required for long term QoL.

\section{Acknowledgements}

The authors thank Anne Collins for editing the English text and Raffaella Bertolotti, Sabina Boselli, Daniela Brambilla and Claudia Crescio for data management.

\section{Footnote}

Conflicts of Interest: The authors have no conflicts of interest to declare.

Ethical Statement: The study was approved by the European Institute of Oncology Ethics Committee (No. R574/17IE0607 15.03.2017) and written informed consent was obtained from all patients.

\section{References}

1. Chernow B, Sahn SA. Carcinomatous involvement of the pleura: an analysis of 96 patients. Am J Med 1977;63:695-702.

2. Raju RN, Kardinal CG. Pleural effusion in breast carcinoma: analysis of 122 cases. Cancer 1981;48:2524-7.

3. Kolschmann S, Ballin A, Gillissen A. Clinical efficacy and safety of thoracoscopic talc pleurodesis in malignant pleural effusions. Chest 2005;128:1431-5.

4. Roberts ME, Neville E, Berrisford RG, et al. Management of a malignant pleural effusion: British Thoracic Society Pleural Disease Guideline 2010. Thorax 2010;65 Suppl 2:ii32-40.

5. Davies HE, Mishra EK, Kahan BC, et al. Effect of an indwelling pleural catheter vs chest tube and talc pleurodesis for relieving dyspnea in patients with malignant pleural effusion: the TIME2 randomized controlled trial. JAMA 2012;307:2383-9.

6. Olfert JA, Penz ED, Manns BJ, et al. Cost-effectiveness of indwelling pleural catheter compared with talc in malignant pleural effusion. Respirology 2017;22:764-70.

7. Thomas R, Fysh ETH, Smith NA, et al. Effect of an Indwelling Pleural Catheter vs Talc Pleurodesis on Hospitalization Days in Patients With Malignant Pleural Effusion: The AMPLE Randomized Clinical Trial. JAMA 2017;318:1903-12.

8. Bertolaccini L, Viti A, Paiano S, et al. Indwelling Pleural Catheters: A Clinical Option in Trapped Lung. Thorac Surg Clin 2017;27:47-55.

9. Narayanan G, Pezeshkmehr A, Venkat S, et al. Safety and efficacy of the PleurX catheter for the treatment of malignant ascites. J Palliat Med 2014;17:906-12.

10. Azzopardi M, Porcel JM, Koegelenberg CF, et al. Current controversies in the management of malignant pleural effusions. Semin Respir Crit Care Med 2014;35:723-31.

11. Bethune N. Pleural poudrage: new technique for the deliberate production of pleural adhesion as preliminary to lobectomy. J Thorac Surg 1935;4:251-61.

12. Dresler CM, Olak J, Herndon JE II, et al. Phase III intergroup study of talc poudrage vs talc slurry sclerosis for malignant pleural effusion. Chest 2005;127:909-15.

13. Boshuizen R, Thomas R, Lee Y. Use of indwelling pleural catheter for management of malignant pleural effusions: the advantages. Curr Respir Care Rep 2013;2:93-9.

14. Dresler CM, Olak J, Herndon JE 2nd, et al. Phase III intergroup study of talc poudrage vs talc slurry sclerosis for malignant pleural effusion. Chest 2005;127:909-15.
Cite this article as: Petrella F, Maisonneuve P, Borri A, Casiraghi M, Donghi S, Durkovic S, Filippi N, Galetta D, Gasparri R, Guarize J, Lo Iacono G, Mariolo AV, Tessitore A, Spaggiari L. Pleural catheters after thoracoscopic treatment of malignant pleural effusion: a randomized comparative study on quality of life. J Thorac Dis 2018;10(5):2999-3004. doi: 10.21037/ jtd.2018.05.49 